\title{
"You Should Maybe Work Together a Little Bit": Formulating Requests in Interprofessional Interactions
}

\author{
David Pichonnaz' (D), Liliane Staffoni ${ }^{2}$, Camille Greppin-Bécherraz ${ }^{2}$, \\ Isabelle Menia-Knutti ${ }^{3}$, and Veronika Schoeb ${ }^{2}$
}

\begin{abstract}
Based on an empirical analysis of video-recorded collaborative practice situations, this article looks at different ways in which a health professional can direct a request to another professional with the aim that he or she performs an action. Using a corpus of video-recorded interactions in different institutional settings and types of situations, it looks at how requests are formulated, showing that they can range from authoritative to mitigated, direct to indirect, and explicit to implicit. The study shows that professionals use a great deal of strategies to preserve politeness and each other's right not to be told what to do, aiming at mitigating the "face-threatening" aspect of requests. However, by doing so, they frequently produce unclear statements which can impede good communication and professional collaboration.
\end{abstract}

\section{Keywords}

requests; interprofessional collaboration; conversation analysis; qualitative; video recordings; Switzerland

\section{Introduction}

Requests directed from a professional to a member of another profession appear to be an important phenomenon in relation to interprofessional collaboration (IPC), as it frequently occurs in day-to-day collaborative practices. It has, however, not been addressed in the literature about professional practices and IPC. We understand requests as discursive actions, "speech acts that try to get another to do something" (Goodwin, 1990, p. 157). We should add "or not to do something." They are therefore "language functions which are expressions of a speaker's intention and which are used not to convey information, but which constitute an action in themselves" (Flöck, 2016 , p. 34). Requesting is a topic of interest in the field of interactional and conversation analysis but has mostly been looked at in ordinary conversations. Although being "one of the most basic and ubiquitous activities in social interaction" (Drew \& Couper-Kuhlen, 2014, p. 1), requests are usually not seen as an easy or preferred mode of interaction in ordinary conversations. Individuals even tend to try to avoid making them (Heinemann, 2006). This has been analyzed as a result of the "face-threatening" (Brown \& Levinson, 1987) character of requests. Requests and "orders" threaten the "negative face" of actors, which is "the want of every "competent adult member' that his actions be unimpeded by others" (Brown
\& Levinson, 1987, p. 62). In short, requests "limit the hearer's freedom of choice" (Flöck, 2016, p. 34). Therefore, language pragmatics studies have shown that actors tend to "seek to avoid these face-threatening acts, or will employ certain strategies to minimize the threat" (Brown \& Levinson, 1987, p. 68).

Requests have been mainly studied in family and mundane conversations (Curl \& Drew, 2008), and between service providers and recipients - where they remain problematic (Heinemann, 2006; Lindström, 2005; West, 1990). One could think that, in institutional settingswhere requests are frequent modes of interactions and necessary to conduct work - they are less problematic. However, our research shows that it is far from being the case. To address the issue of the face-threatening aspect of interprofessional requests, we will investigate the

\footnotetext{
'School of Social Work, University of Applied Sciences and Arts Western Switzerland (HES-SO Valais-Wallis), Sierre, Switzerland ${ }^{2}$ School of Health Sciences (HESAV), University of Applied Sciences and Arts Western Switzerland (HES-SO), Lausanne, Switzerland ${ }^{3}$ Physiotherapie Isabelle Knutti, Biel/Bienne, Switzerland

\section{Corresponding Author:}

David Pichonnaz, Assistant Professor, School of Social Work, University of Applied Sciences and Arts Western Switzerland (HES-SO Valais-Wallis), Rte de la Plaine 2, CH-3960 Sierre, Switzerland. Email: david.pichonnaz@hevs.ch
} 
Table I. Data Collected.

\begin{tabular}{|c|c|c|c|}
\hline Types of Institutions & Types of Situations Video-Recorded & $\begin{array}{l}\text { Duration of Videos } \\
\text { Total }=59 \mathrm{hr} 25 \mathrm{~min}\end{array}$ & Language Region \\
\hline $\begin{array}{l}\text { University hospital (internal } \\
\text { medicine and pneumology) }\end{array}$ & Interprofessional meetings, Medical visits & $23 \mathrm{hr} 24 \mathrm{~min}$ & French \\
\hline District hospital (oncology) & Interprofessional meetings & I hr $55 \mathrm{~min}$ & Italian \\
\hline Rehabilitation centers & $\begin{array}{l}\text { Interprofessional meetings, Instructional } \\
\text { sessions }\end{array}$ & $14 \mathrm{hr} 25 \mathrm{~min}$ & French, German, Italian \\
\hline $\begin{array}{l}\text { Socio-pedagogic } \\
\text { institutions }\end{array}$ & $\begin{array}{l}\text { Interprofessional meetings, Joint therapy } \\
\text { sessions, Instructional sessions }\end{array}$ & $18 \mathrm{hr} 13 \mathrm{~min}$ & French, Italian \\
\hline Nursing home & Interprofessional meetings & I hr $28 \mathrm{~min}$ & German \\
\hline
\end{tabular}

question of how requests are formulated and discuss the consequences of these formulations on interprofessional collaboration. Although analysis concentrates on how requests are formulated, we reflect and elaborate hypothesis about why they are so.

This qualitative study aims at better understanding the detailed mechanisms of interactions and human communication. The objective is to provide an in-depth analysis of requests without measuring the probability of a specific request to occur in a given context. Therefore, we do not provide figures about the number of occurring types of requests but concentrate on their forms and modalities, implications, issues, and consequences. Because these social mechanisms have been overlooked, a qualitative approach needed to be applied first. These results could constitute a base on which further research could be conducted.

\section{Method}

This study is part of a bigger investigation regarding collaborative practice in a Swiss health care context. The research draws on video-taped collaborative practice situations, which were collected within a Swiss National Science Foundation funded project about IPC (Nr. 100017_159327). Between 2016 and 2018, we filmed nearly 60 hours of collaborative practices in 11 institutions/departments within a university hospital, a district hospital, rehabilitation centers, socio-pedagogic institutions (for young people and for adults with neurologic disabilities), and a nursing home across the three linguistic parts of Switzerland. ${ }^{1}$ A multitude of interprofessional situations were video-recorded $(N=$ 148; 90 in French, 48 in German, 10 in Italian) - as presented in Table 1.

The video-recorded situations involved a total of 226 professionals belonging to various health professions (physicians, nurses, physiotherapists, occupational therapists, language therapists, psychologists, etc.) and to social work. Videos were described in full length. Sequences involving requests were transcribed using Conversation Analysis conventions (Jefferson,
2004). Conversation Analysis aims to "capture the understandings and orientations displayed by the participants themselves" (Clayman \& Gill, 2004). This approach takes into consideration that (a) "talk is context shaped," meaning that participants refer to preceding talk; (b) "talk is context-renewing," that is, participants project the next actions; and (c) mutual understanding is constructed through the sequential architecture of intersubjectivity (Heritage, 2005).

Before filming, we conducted ethnographic observations and informal interviews in each institution to understand the organizational culture, to select the situations to be filmed, and to prepare video recordings (Heath et al., 2010). Video recording requires a great deal of information transmission and negotiation to gain the consent of all filmed persons (Pichonnaz et al., 2017). All participants signed an informed consent form, stating that they agreed that the video recordings be used for research purposes. They could also accept or not that the sequences be used for training purposes. Video recordings were stored on external drives only, kept in a locked cupboard. To assure anonymity, transcribed sequences never mention elements that could identify the participants (e.g., names of persons or institutions). The project obtained approval from the Cantonal Ethic Committee (Nr. 2015-00208).

\section{Results}

Inductive analysis of the corpus of requests shows that they can be typified in relation to three variables: whether they are in an imperative or mitigated form (i.e., their authoritative character is moderated), direct or indirect, and whether they are explicit or implicit (see Figure 1). An explicit request is formulated as an obvious request, whereas an implicit one is a statement to which someone respond to by accepting to do something, although it does not look as a request. A direct request is directed at a specific person or group of persons, whereas an indirect one is not. This specific person or group can be designated verbally or non-verbally. The observed combination of these properties is shown 


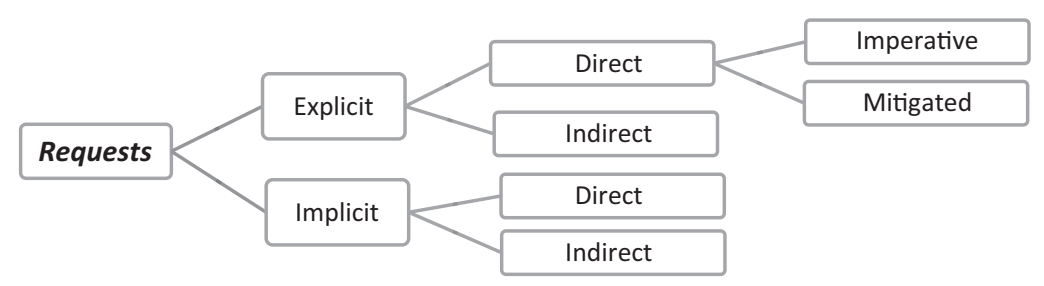

Figure I. Types of requests with reference to the article sections.

in Figure 1, the elements of which will be presented hereinafter.

\section{Direct, Explicit, and Imperative Requests (Authoritative Character)}

We call direct and explicit requests those that are clearly formulated as such and are directed to someone or to a specific group or profession. This kind of request uses an imperative, or a present tense which acts as an imperative, as shown in the two following excerpts taken from our data:

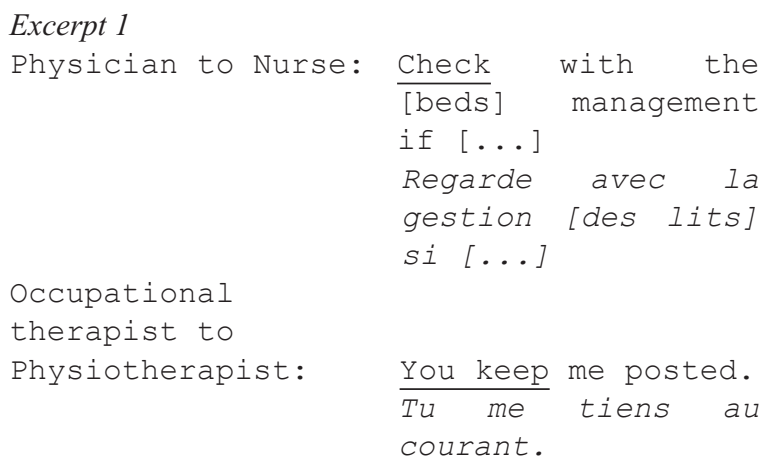

Both these formulations give an authoritative character to the requests and construct the speakers as clearly "entitled" (Curl \& Drew, 2008) to formulate and address them. No specific strategy is applied to comply with the conventional "politeness" and "tact" rules (Leech, 1983). Therefore, this kind of formulating is not always accepted by those they are addressed to. In the following excerpts, a direct, explicit and imperative request addressed to a junior physician by a liaison nurse provokes a reaction, confirming that a request with an authoritative character can be problematic. The (male) physician is currently a resident in internal medicine ("assistant physician"). As such, he is responsible for a group of patients, under the supervision of a senior physician who is not participating in this meeting. The (female) liaison nurse has a key role in this internal medicine unit, managing patient flow (incoming and discharge) as well as liaising with and organizing out-of-hospital care. The discussion takes place in the unit corridor, in the presence of another (male) nurse. These three individuals know each other well. They closely work together on a daily basis. The liaison nurse announces to the physician that she has organized the transfer of a patient with a severe condition to another institution and makes a request to the physician to pass on information further.

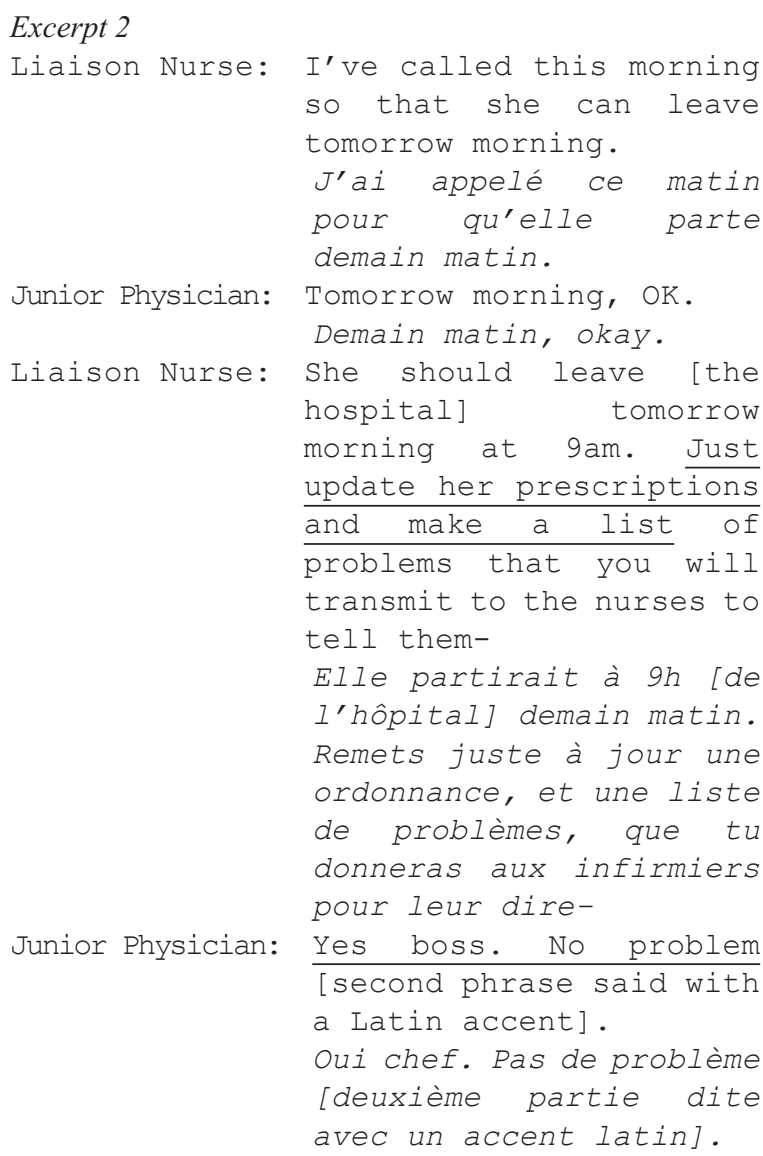

The liaison nurse's request is formulated in an imperative form. The junior physician interrupts her by saying "Yes boss." Said as a joke, the physician's response can be analyzed as contributing to make a norm explicit. It is not a direct reproach addressed to the liaison nurse: The 
imperative request might not even have fundamentally irritated him, as shown by the fact that he jokily imitates a Latin (non-local) accent. However, his reaction indicates that she has transgressed a social norm: Requests should not be authoritative. Because the liaison nurse is not "vastly superior in power" (Brown \& Levinson, 1987, p. 69) to the junior physician, the use of the imperative here, if we follow Brown and Levinson's (1987) Politeness Theory, should be linked either to the fact that the facethreatening dimension of such a request is "suspended in the interests of urgency or efficiency" or that the request is "clearly in [the physician's] interest and do not require great sacrifices of [the nurse]" (p. 69). We can think, as a hypothesis, that both reasons apply: The nurse is talking rapidly (as in daily interprofessional meetings, when she lists the situation of several patients), of several patients in a row (efficiency), and she is reminding the physician to do things only he is entitled to do (his interest).

\section{Direct and Explicit Requests With a Mitigated Authoritative Character}

As literature on ordinary conversations has extensively shown, imperative requests are not taking place frequently (see, for example, Brown \& Levinson, 1987; Curl \& Drew, 2008). Our data show that direct and explicit requests are frequently formulated in a way that mitigate their authoritative character. The most common resource used for that purpose is the conditional tense, as in the excerpt below where a manager asks a nurse whether she can conduct an individual meeting with a new resident in a home for people with disabilities. This dialogue happens during the weekly interprofessional meeting in this socio-pedagogic institution in the German part of Switzerland. The manager asks the nurse whether she can become the referent for a new resident (in this institution, each patient has a nurse or social worker as referent):

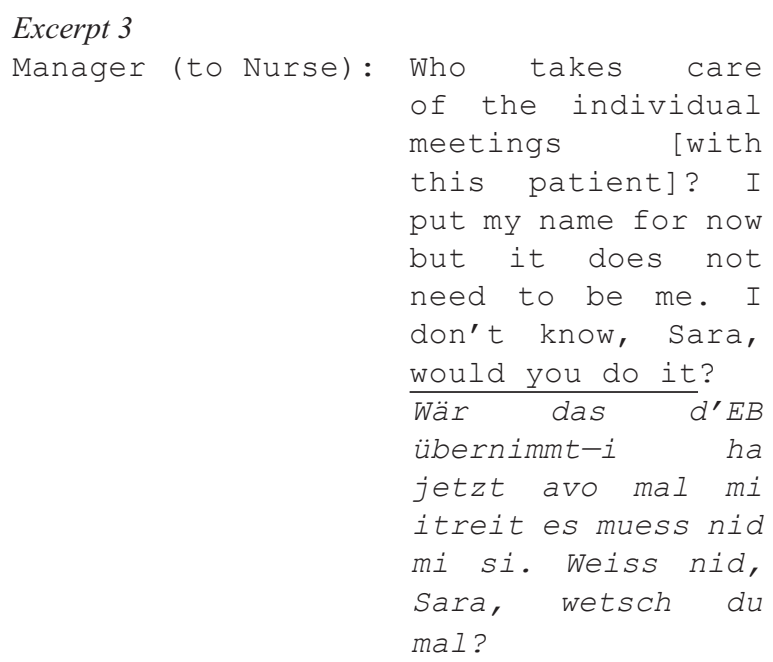

In this case, "Would you do it?" is the conditional version of "Do it!" It also implies using an interrogative form, that is, formulating a question, a form that has been analyzed as more "diplomatic and polite" in a study of palliative care interprofessional communication (Arber, 2008, p. 1331). In our data, such formulation often starts with "I would find it good if . .."; "Could you ...."; "It might be good to ..."; "I wonder if (it was possible to) . . ."A second way of formulating less authoritative requests is the use of downtoners ${ }^{2}$ (especially "a bit") or understaters $^{3}$ (especially the adverb "maybe").

An example of such a mitigation can be taken from an interprofessional meeting in a hospital oncology unit. Various health and social care professionals are discussing all current patients in the unit. A (female) junior physician starts talking of a new patient with a severe oncological disease but is immediately interrupted by a (female) senior physician, who is head of the unit.

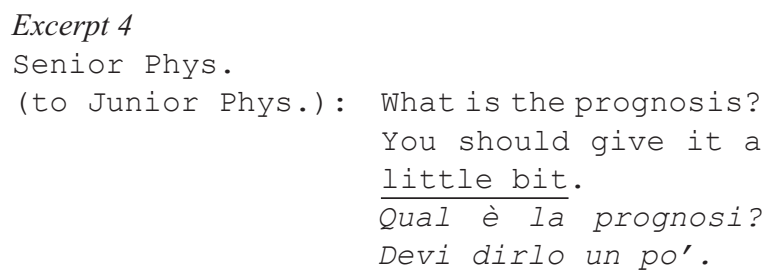

In this sentence, it is obvious that a life prognosis can be given or not, but not "a little bit" or "a lot." The downtoner "a little bit" has a function of giving a less authoritative look to the request. Understaters, which are widely used too, can be exemplified by another excerpt, from a conversation between a nurse, a senior physician, and a social worker. These professionals are discussing a patient case in a unit specialized in the treatment of chronic lung diseases. This conversation happens within a weekly interprofessional meeting during which patients with significant changes in their health or personal conditions are discussed. The nurse and then the physician ask the social worker to improve her collaboration with social workers from another department. The meeting involves other professionals (physicians, including a psychiatrist, and a psychologist).

Excerpt 5

Nurse:

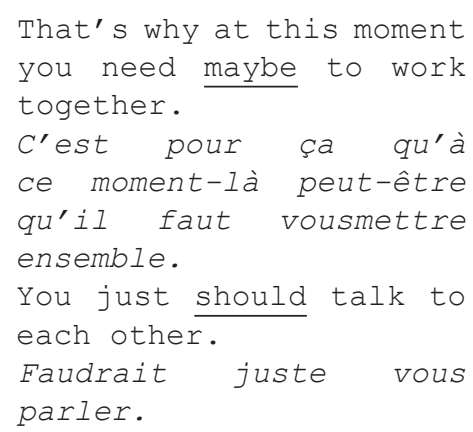




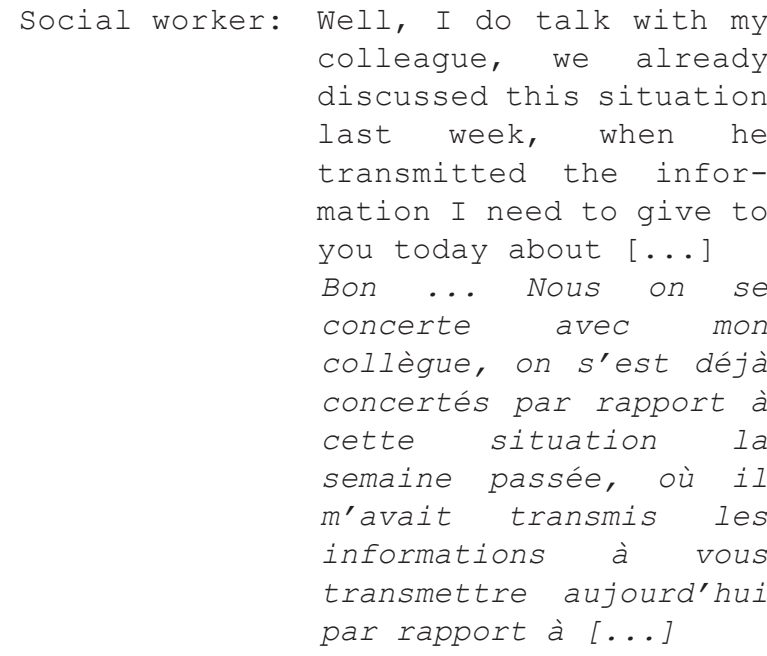

The first formulation of the request, made by the nurse, uses the most common understater: "maybe." When the physician confirms the request, she uses the conditional but no downtoner or understater. Therefore, when compared, the second request appears more authoritative than the first one. It could be argued that, as a physician, she feels more entitled to do so: Brown and Levinson (1987, p. 69) state that power differences are a common cause for more authoritative requests. Our data are insufficient to demonstrate it in this case. However, the response of the social worker clearly shows that she acknowledges the request. Because she justifies herself by stating what she has already done, we can also conclude that she considers the request as legitimate, or that she is not able to contest it.

Finally, humor can be used as a way of making requests more acceptable (as already shown in Excerpt 2), when a joke is associated to a direct and explicit request. ${ }^{4}$ This is the case, for example, within an interaction in a rehabilitation hospital, during an interprofessional meeting where a head physician addresses a request to an occupational therapist, just after having raised an issue that prevents a patient to be able to go back home:

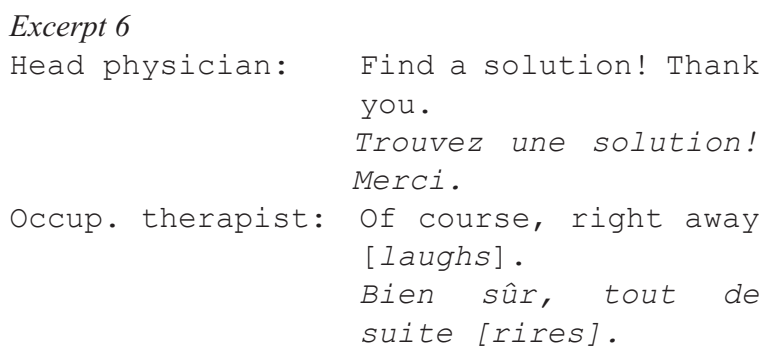

The way the occupational therapist responds and then laughs right after the head physician's request clearly shows that its formulation is meant as a joke. The issue raised before is, however, real — and important-as the possibility for the patient to be able to live in her private home is at stake. The head physician's joke is nevertheless understood as a real and serious request by the occupational therapist, who responds by explaining what she has planned for this patient (not shown in the excerpt above). This includes therapies that could contribute to help with the mobility issue that has been raised and framed as "problematic" by the head physician.

If we summarize the different strategies used by health professionals to mitigate the authoritative character of their requests, it consists of using interrogative forms, conditional tenses, downtoning and understating words, as well as humor. These mechanisms apply to direct and explicit requests only, but a great deal of them are indirect and/or implicit.

\section{Indirect but Explicit Requests}

A great deal of requests are indirect: Even when explicit, they are often not directed at a specific person, and not even to a specific profession. Formulating such a request is most often based on the use of the French impersonal pronoun "on" and the German equivalent "man," which translates into English as the impersonal "one" or "you" (when the latter is not directed at someone). Also frequently used is the passive form (e.g., "It is a patient to whom one/you need to give extra care" or "This patient should be given extra care"). It can also be an inclusive "we" which does not state who among "us" is supposed to respond to the request, as in the following excerpts, in both of which a physician formulates a request during an interprofessional meeting (comprising nurses and other professionals).

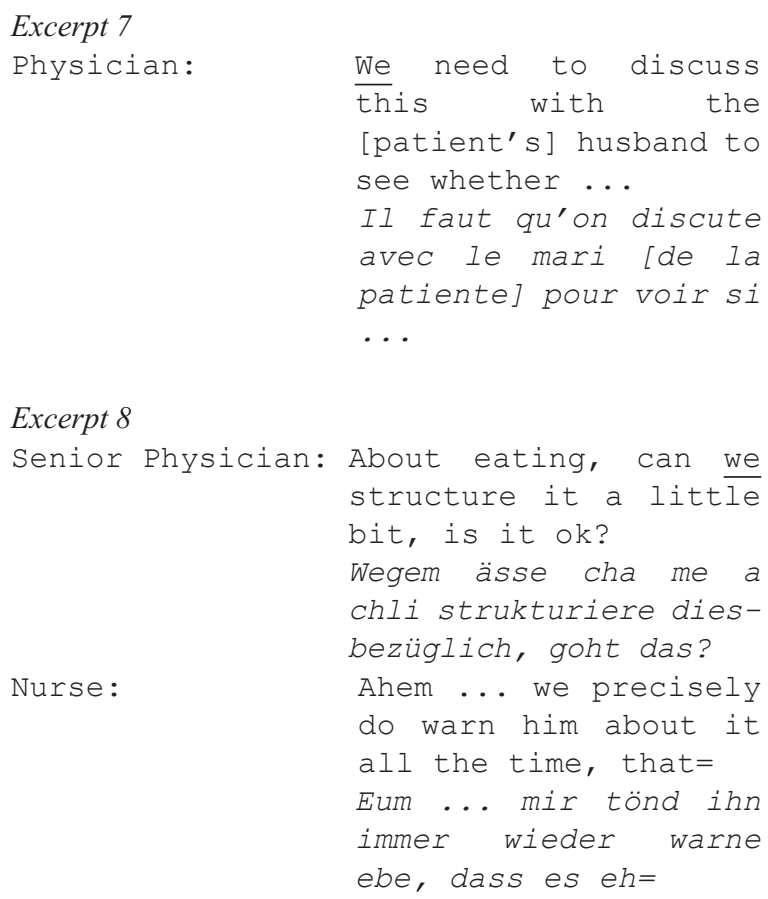

Excerpt 8

Senior Physician: About eating, can we structure it a little 


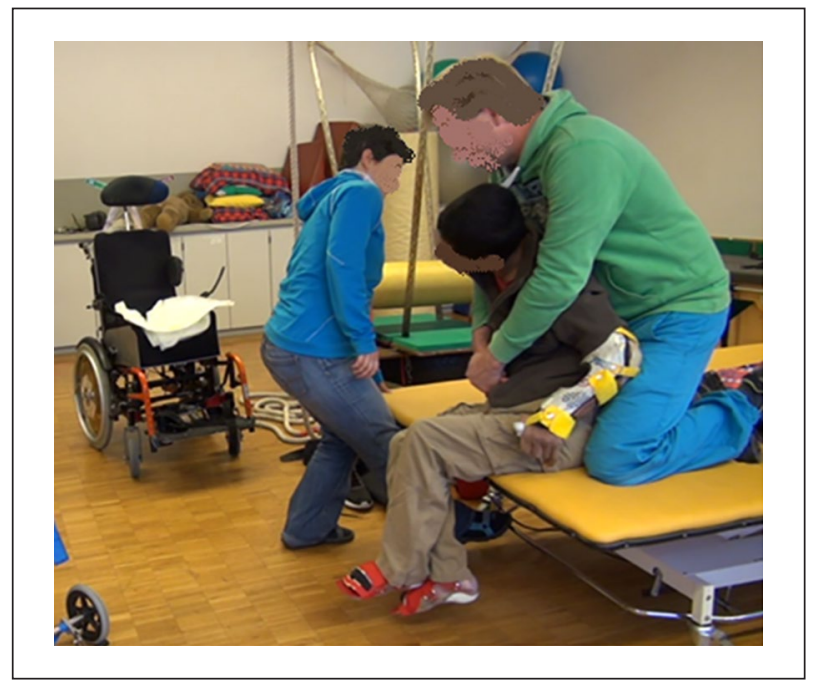

Picture I. Request directed at the patient.

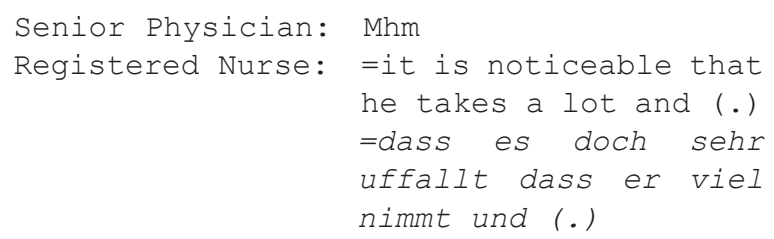

In both these cases, and frequently in our data, the pronoun "we" includes everyone who is present, with the result that nobody is specifically requested to accomplish the task. This indirectness is reinforced in French by the fact that the pronoun used ("on") is at the same time the equivalent of the impersonal pronoun "one" and the pronoun "we."

Another way of performing indirect requests to colleagues is to direct them to the patient. In our data, it happens in particular in a home for children with neurological disabilities. In one of the filmed sequences, an occupational therapist (left in Picture 1) and a physiotherapist (on the right) have just finished a joint therapy session with a young boy who can hardly move by himself and can only communicate with gestures but not talk.

In this situation, the physiotherapist says to the patient: "Emma [= the occupational therapist] could maybe bring the wheelchair, and then we're good.," after which the occupational therapist immediately complies. In this situation, the physiotherapist asks her colleague to bring the wheelchair nearer but directs his request to the patient. He also uses the usual understater "maybe." After that, the occupational therapist asks the patient, "Are you well seated?" The patient seems to disagree and utters a sound. The occupational therapist then translates the patient's answer by stating: "No he's not well seated," which leads the physiotherapist to put the patient in a better position. When the occupational therapist asks the patient whether he is well seated, and relays the negative answer to her colleague, she actually requests the physiotherapist to perform an action. This request is therefore not addressed directly to the physiotherapist and is also implicit (not formulated as a request, see hereinafter).

\section{Implicit but Direct Request}

Despite their implicitness, requests not formulated as such can nonetheless be formulated in a direct way. The following excerpt shows an interaction between an occupational therapist and a nurse within an interprofessional meeting that concerns the elaboration of a patient's care plan, in a neurorehabilitation hospital. Although this excerpt involves two professionals, the meeting also includes physicians, a physiotherapist, and a liaison nurse.

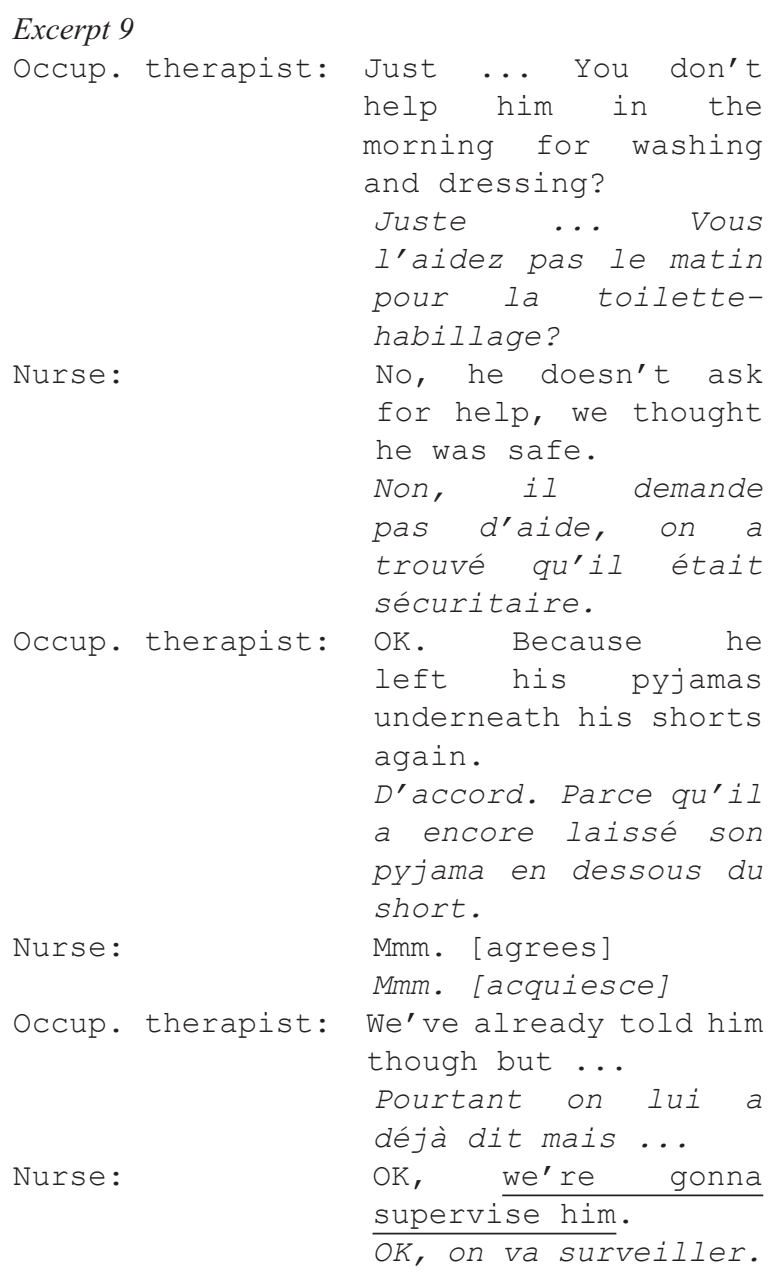

The nurse explicitly formulates a response to a request (last line) by stating she or her colleagues will supervise the patient. However, none of the occupational therapists' interventions (first three lines) are 
explicit requests, although her question (first line) is directed to the nurse. It shows that acknowledging a direct request does not require that it has been formulated as such, as it was the case in the situation above (with the picture), where the occupational therapist states, about the patient: "No he's not well seated" to have her colleague perform an action. In this other interaction about washing and dressing, both professionals do not have the same objectives. The occupational therapist follows a cognitive rehabilitation goal: The patient must put his clothes in the correct order (later in the conversation she states that she has already told the patient not to dress like that - data not shown here). The nurse has another objective in mind, which is to guarantee the patient's safety. ${ }^{5}$ However, this disagreement is not discussed in this interaction.

\section{Implicit (and Often Indirect) Requests}

Although the example above show that an implicit request can be a direct one, those are most of the time formulated in an indirect way, as in both excerpts below. The first one involves a junior physician and a nurse, in the internal medicine department of a large hospital, discussing the treatment of a patient during an informal meeting in the unit corridor. The second one, happening in the same department, involves a physiotherapist discussing with a registered nurse, on a Friday afternoon, about the program of the upcoming weekend. Nurses work on weekends, whereas physiotherapists do not in this department.

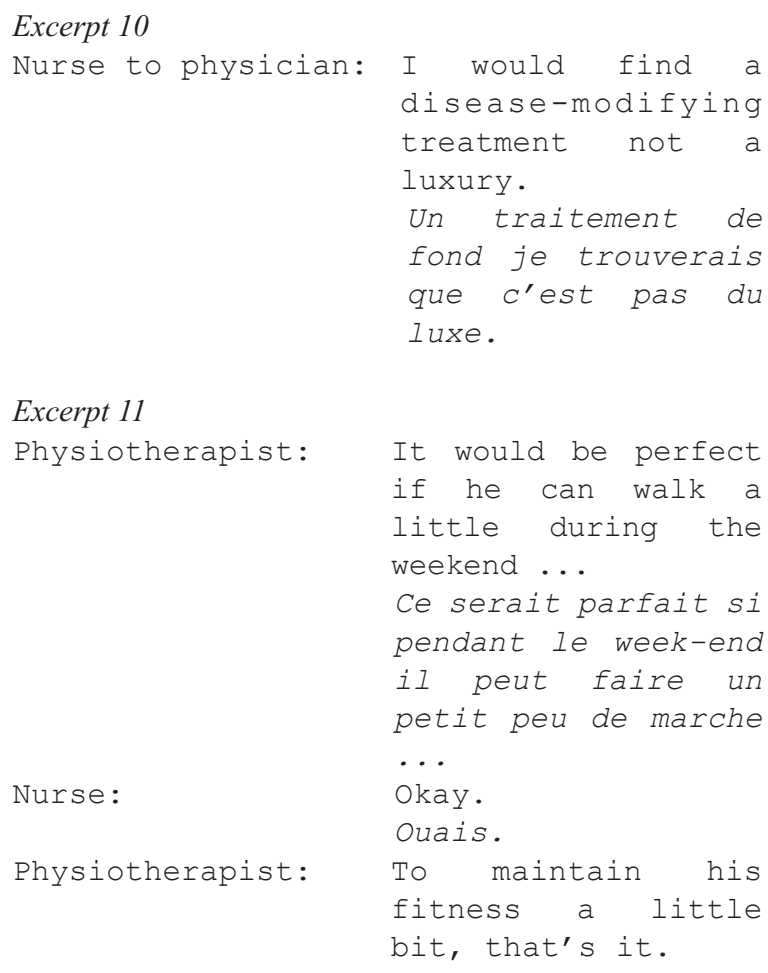

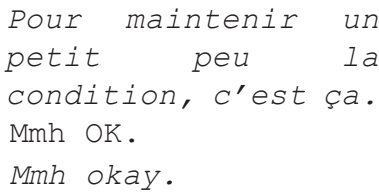

In both these situations, requests are not formulated as such and no introductory question or statement directs them to someone: They are indirect and implicit. Another way of making indirect requests consists of using a specific type of framing. For example, in an interprofessional meeting about patients with a specific chronic disease, a senior physician insists on a young patient's psychological problems to attract the psychologist's attention and to involve her in the patient's care plan, without directly asking for her opinion. The intention of the senior physician to involve the psychologist derives, first, from the content of her message: She stresses the fact that the pediatric team, who took care of the patient until recently, has not assessed the actual gravity of the patient's mental health issues. Second, it derives clearly from the way she communicates her message non-verbally (body language): Although her gaze moves from one participant to another, she constantly talks specifically to the psychologist and the psychiatrist, addressing them through her body language. Later in the discussion, after other issues about the family situation of the patient have been raised, she states that:

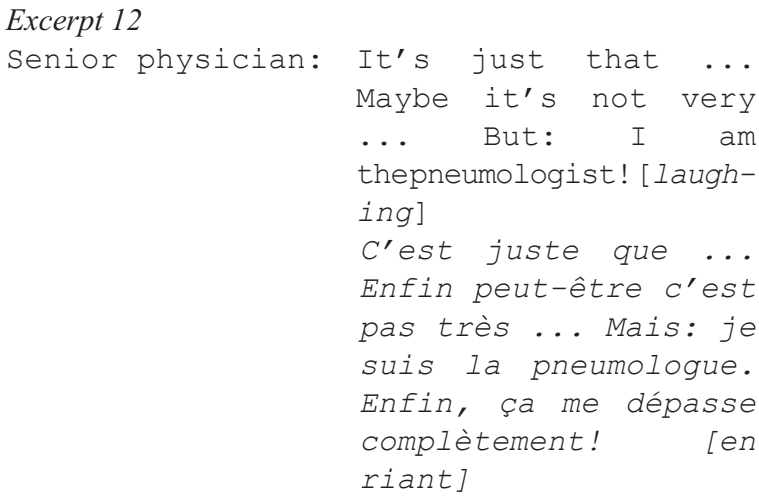

This excerpt shows the senior physician exposing the limit of her expertise: "I am the pneumologist" intends to specify that she cannot count on knowledge about psychological therapy, child protection, and youth homes placement procedures. This statement can also be analyzed as a request for help directed to the psychologist and the social worker. Later in the same meeting, professionals do talk about the problematic character of the patient's family environment. The discussion leads to a suggestion from the psychologist to activate the child protection agency. All agree on this possibility, which brings the senior physician to frame the situation as 
"urgent," which opens a window for a new solution proposed by a psychiatrist: The patient could be placed in a specialized home (see excerpt below).

Excerpt 13

Psychiatrist:

Senior physician: I think he needs to be separated from his family.

Ah moi je pense qu'il faut le sortir de son milieu familial.

Psychiatrist: It looks like he's doing better when he is in the hospital ... I mean: he would be better in a ... Maybe ... We would need his approval, it is complicated, but let's say maybe we need to ... If it is not incompatible with his disease, I think that ...

Il a l'air d'aller mieux quand il est à I'hôpital ... Je veux dire: il serait mieux dans une ... Peut-être ... Après il faut qu'il soit d'accord, c'est compliqué, mais disons peut-être qu'il faut ... si c'est pas incompatible avec sa maladie, je me dis bon là ...

$\begin{array}{ll}\text { Senior physician: } & \text { No, no, it's not a } \\ & \text { problem with his } \\ & \text { disease. } \\ & \text { Non non, avec la } \\ & \text { maladie c'est vraiment } \\ & \text { pas un problème. } \\ & \text { Then, it seems to me } \\ & \text { that we should explore } \\ & \text { this possibility } \\ \text { Psychiatrist: } & \text { anyways, to find some } \\ & \text { place for young } \\ & \text { people, with social } \\ & \text { workers [... . . } \\ & \text { Alors à ce moment-là, } \\ & \text { il me semble qu'il } \\ & \text { faudrait explorer } \\ & \text { quand même cette } \\ & \text { possibilité-là } \\ & \text { trouver un truc un } \\ & \text { peu pour les jeunes, } \\ & \text { avecun peu des éduc. } \\ & \text { [... I. }\end{array}$

As shown in the beginning of this excerpt, the psychiatrist formulates several implicit requests ("One would be a little keen to send him in a home."), even at the end of the sequence ("We should explore this possibility anyways."). Later in the discussion, he states that "We need social work with this case": His implicit request begins therefore to be directed at someone, as he mentions the profession involved but not the person. Before he explicitly mentions "social work," he therefore implicitly and indirectly asks the social worker who is in the meeting to talk about placement possibilities. The psychiatrist is usually not participating in this meeting and does not identify who the social worker sitting at the table is: This might explain why his request is both implicit and indirect. The senior physician who is leading the meeting, but does not know very well the social worker (new in this ward), is more assertive about what should be done ("I think he needs to be separated from his family"). The requests remain nevertheless implicit and indirect. Despite this, the social worker understands it as a request: She replies that the patient placement cannot be implemented, due to funding issues - which implicitly says that she does not agree with it.

\section{Discussion}

In interactional, linguistic, and conversational analytic literature, requests between professionals in institutional contexts have rarely been studied. Research concentrates on requests in everyday conversations, initially those directed by adults to children, with the exception of a recent study by Sterie and González-Martínez (2017) investigating requests in hospital settings. These authors 
demonstrate that requests directed by nurses to porters are explicit, whereas those directed to physicians are most often implicit. Nurses tend to report problematic situations to physicians, and expect the latter to take decisions, including prescriptions for medications. However, this study, as well as others, has not looked at the direction of requests. ${ }^{6}$ Because our research looks at requests in interprofessional (team) settings, their direction seems to be more of an issue than in ordinary conversations. We have shown that requests are frequently not addressed to someone in particular, speakers often using impersonal pronouns or plurals such as "one" and "we," as well as passive forms such as "It needs to be done" or even directing the request to the patient. In parallel, we have shown that requests are frequently mitigated in their authoritative character, using interrogative forms, conditional tenses, downtoners (e.g., "a bit") or understaters (e.g., "maybe"), and humor. They are also often implicit, even when directed to someone, by being statements not formulated as requests, or when professionals purposely display a lack of expertise or frame problems in a certain way so that other professionals feel concerned. Both mitigation and implicitness can be considered as ways of dealing with the "face-threatening" (Brown \& Levinson, 1987) aspect of requests, the fact that they challenge the freedom of those they are addressed to. One could think that this is less of an issue in professional and hierarchical institutional settings, but our study shows that professionals use a great deal of strategies to preserve politeness and each other's right not to be told what to do. This demonstrates that the problematic aspect of requests is little impeded by professional relations. However, our data suggest, consistent with studies of ordinary conversation, that power detention (Brown \& Levinson, 1987) and entitlement (Curl \& Drew, 2008) deriving from hierarchical position allow actors to formulate requests in a more authoritative or explicit manner. In one of the cited excerpts where the assistant physician answers "Yes, boss" to the liaison nurse (Excerpt 2), it is likely to derive from the fact that she is not completely entitled to address direct, explicit and imperative requests to the physician.

If we think of requests in relation to the issues raised by the literature and guidelines about IPC, we can relate it to the communication, hierarchy, and knowledge-sharing problems. Research shows that IPC needs "healthy and respectful communication" (Ryan, 2012) that is efficient (Kosremelli Asmar \& Wacheux, 2007; Thomson et al., 2015; Zwarenstein et al., 2013). Communication should not be hierarchy-dependent or shaped by medical dominance (Alexanian et al., 2015; Hall, 2005; Reeves et al., 2015; Shaw et al., 2007; Thomson et al., 2015), and should avoid "interpersonal misunderstanding" (Mickan et al., 2010). Making direct and explicit requests can be considered as helping to avoid misunderstandings. Clear and targeted requests are known to be more efficient in terms of good communication (Rosenberg, 2003). Such requests make it possible to generate discussions about the intended purpose of each professional, the goals pursued, helping to reach agreement about a common target (Smith-Carrier \& Neysmith, 2014). It can also make it possible to raise disagreements and tensions, and to discuss them. Even when it is not possible to reach a common agreement, it can be considered helpful that each professional can express his or her views, which is enhanced when communication is clear.

D'Amour and Oandasan (2005) distinguish "interdisciplinarity" from what they call "interprofessionality" and define the latter as a process of reconciliation of professional differences and contrasting views, which necessitates "continuous interactions and knowledge sharing between professionals." The guidelines regarding IPC also mention the notion of knowledge sharing, captured in Centre for the Advancement of Interprofessional Education (CAIPE's definition: "Interprofessional health care occurs when various professions learn from and about each other to improve collaboration and the quality of care" (Barr et al., 2017). IPC is therefore enhanced when professionals know not only about each other's expertise but also about each other's constraints. Indirect or implicit requests make it impossible to include the "contingencies" (Curl \& Drew, 2008) of those they are addressed to, that is, the conditions under which the request can be responded to and the obstacles the person could face to respond to it. A direct, explicit request that takes into account the contingencies of those it is addressed to would need the speaker to question his or her entitlement to request, but more importantly to show interest in the person. Making direct, explicit requests that include other's contingencies would therefore be an implementation of the IPC guidelines, as it would take into account other's constraints.

\section{Conclusion}

Our analysis shows that requests can be formulated in an imperative or mitigated form (i.e., their authoritative character is moderated), can be directed to someone or not (verbally or non-verbally), and can be explicitly formulated as requests or not. An explicit request is formulated as an overt request, whereas an implicit one is a statement that is treated as a request, because someone responds to it by performing an action or granting the request. In our data, various language devices make it possible for professionals to formulate requests that are frequently not addressed to someone in particular and to mitigate their authoritative character. This tendency can be considered as impeding efficient communication and 
leaving tensions and disagreements implicit in interprofessional teams - therefore being obstacle to good collaboration.

Based on this analysis, the following recommendations can be drawn. First, requests should be directed to a specific person: Indirect requests cannot be properly responded to, as participants do not feel addressed by it. However, directness can be difficult to implement in strongly hierarchical institutions, when the request is formulated by a person with a lower hierarchical position. Second, implicit requests, although they can help to deal with the face-threatening aspects of requests by mitigating their authoritative aspect, are also problematic, as they do not provide sufficient information to foster open and clear communication. Politeness should be preferred to implicitness to mitigate the authoritative character of requests, by using conditional or interrogatory forms of requests, for example. Moreover, the contingencies of those the requests are addressed to should be taken into account in their formulation. It is therefore recommended that professionals transform implicit and/or indirect requests into explicit and direct ones to gain clarity of communication and designation of responsibilities, and that institutions allow that such requests are formulated by professionals of any rank.

\section{Declaration of Conflicting Interests}

The authors declared no potential conflicts of interest with respect to the research, authorship, and/or publication of this article.

\section{Funding}

The authors received the following financial support for the research, authorship, and/or publication of this article: The research from which this article stems was funded by the Swiss National Science Foundation (Project 100017_159327).

\section{ORCID iD}

David Pichonnaz iD https://orcid.org/0000-0003-2066-8705

\section{Notes}

1. Switzerland is constituted of three main language regions, with people speaking German in the North, French in the West, and Italian in the South.

2. Downtoners are words that aim to reduce the strength of a phrase. They are the opposite of emphasizing words.

3. Understaters are words aiming to state something with less completeness than needed; to minimize or downplay.

4. Schöpf et al. (2017) have shown that humor can also be used in professional-patient interactions to decrease the power asymmetry.

5. Maximizing patients' security can frequently be done to the detriment of other principles or objectives, as we have shown about work with residents in nursing homes (Pichonnaz et al., 2020).

6. Classical theory in pragmatics of language and linguistics tend to consider that a request is indirect when it is not formulated in an imperative form. What we call a mitigated phrasing such as "Can you please do ..." is therefore considered as an indirect request in this stream of research (Flöck, 2016, p. 17).

\section{References}

Alexanian, J. A., Kitto, S., Rak, K. J., \& Reeves, S. (2015). Beyond the team: Understanding interprofessional work in two North American ICUs. Critical Care Medicine, 43(9), 1880-1886. https://doi.org/10.1097/CCM.0000000 000001136

Arber, A. (2008). Team meetings in specialist palliative care: Asking questions as a strategy within interprofessional interaction. Qualitative Health Research, 18(10), 13231335. https://doi.org/10.1177/1049732308322588

Barr, H., Ford, J., Gray, R., Helme, M., Hutchings, M., Low, H., Machin, A., \& Reeves, S. (2017). Interprofessional education guidelines. CAIPE.

Brown, P., \& Levinson, S. C. (1987). Politeness: Some universals in language usage. Cambridge University Press.

Clayman, S. E., \& Gill, V. T. (2004). Conversation analysis. In M. A. Hardy \& A. Bryman (Eds.), Handbook of data analysis (pp. 589-606). SAGE.

Curl, T. S., \& Drew, P. (2008). Contingency and action: A comparison of two forms of requesting. Research on Language \& Social Interaction, 41(2), 129-153. https:// doi.org/10.1080/08351810802028613

D'Amour, D., \& Oandasan, I. (2005). Interprofessionality as the field of interprofessional practice and interprofessional education: An emerging concept. Journal of Interprofessional Care, 19(Suppl 1), 8-20. https://doi.org /10.1080/13561820500081604

Drew, P., \& Couper-Kuhlen, E. (2014). Requesting-From speech act to recruitment. In P. Drew \& E. Couper-Kuhlen (Eds.), Requesting in social interaction (pp. 1-34). John Benjamins.

Flöck, I. (2016). Requests in American and British English: A contrastive multi-method analysis. John Benjamins.

Goodwin, M. H. (1990). Directive-response speech sequences in girls' and boys' task activities. In S. McConnell-Ginet, R. Borker, \& N. Furman (Eds.), Women and language in literature and society (pp. 157-173). Praeger.

Hall, P. (2005). Interprofessional teamwork: Professional cultures as barriers. Journal of Interprofessional Care, 19(Suppl. 1), 188-196.https://doi.org/10.1080/13561820 500081745

Heath, C., Hindmarsh, J., \& Luff, P. (2010). Video in qualitative research: Analysing social interaction in everyday life. SAGE.

Heinemann, T. (2006). "Will you or can’t you?" Displaying entitlement in interrogative requests. Journal of Pragmatics, 38(7), 1081-1104. https://doi.org/10.1016/j. pragma.2005.09.013

Heritage, J. (2005). Conversation analysis and institutional talk. In K. L. Fitch \& R. E. Sanders (Eds.), Handbook of language and social interaction (pp. 103-147). Lawrence Erlbaum.

Jefferson, G. (2004). Glossary of transcript symbols with an introduction. In G. H. Lerner (Ed.), Conversation analysis: Studies from the first generation (pp. 13-31). Benjamins. 
Kosremelli Asmar, M., \& Wacheux, F. (2007). Facteurs influençant la collaboration interprofessionnelle: Cas d'un hopital universitaire [Factors influencing interprofessional collaboration: The case of a university hospital] (pp. 57-75). https://basepub.dauphine.fr/bitstream/ handle $/ 123456789 / 2614 /$ wacheux.PDF?sequence $=2 \&$ is Allowed=y

Leech, G. N. (1983). Principles of pragmatics. Longman.

Lindström, A. (2005). Language as social action: A study of how senior citizens request assistance with practical tasks in the Swedish home help service. In A. Hakulinen \& M. Selting (Eds.), Syntax and lexis in conversation: Studies on the use of linguistic resources in talk-in-interaction (pp. 209-230). John Benjamins.

Mickan, S., Hoffman, S. J., \& Nasmith, L. (2010). Collaborative practice in a global health context: Common themes from developed and developing countries. Journal of Interprofessional Care, 24(5), 492-502. https://doi. org/10.3109/13561821003676325

Pichonnaz, D., Bécherraz, C., Knutti, I., Staffoni, L., \& Schoeb, V. (2017). Filmer les soins. Données vidéo et recherche qualitative [Filming Healthcare Settings. Video Recordings and Qualitative Research]. Recherches Qualitatives, 36(2), 63-84.

Pichonnaz, D., Lambelet, A., \& Hugentobler, V. (2020). Désaccords en établissements pour personnes âgées. Analyser les concurrences entre métiers aux contours flous [Disagreements in nursing homes. Analysing the competition between occupations with fuzzy boundaries]. Revue Suisse de Sociologie, 46(1), 97-115. https://doi. org/10.2478/sjs-2020-0005

Reeves, S., McMillan, S. E., Kachan, N., Paradis, E., Leslie, M., \& Kitto, S. (2015). Interprofessional collaboration and family member involvement in intensive care units: Emerging themes from a multi-sited ethnography. Journal of Interprofessional Care, 29(3), 230-237. https://doi.org/ $10.3109 / 13561820.2014 .955914$

Rosenberg, M. B. (2003). Nonviolent communication: A language of life (2nd ed.). PuddleDancer.

Ryan, B. (2012). A Qualitative Study of Medical Social Workers' and Nurses' Perceptions on Effective Interprofessional Collaboration. Master of Social Work Clinical Research Papers. http://sophia.stkate.edu/msw papers/84

Schöpf, A. C., Martin, G. S., \& Keating, M. A. (2017). Humor as a communication strategy in provider-patient communication in a chronic care setting. Qualitative Health Research, 27(3), 374-390. https://doi.org/10.1177/1049 732315620773

Shaw, M., Heyman, B., Reynolds, L., Davies, J., \& Godin, P. (2007). Multidisciplinary teamwork in a UK Regional Secure Mental Health Unit. A matter for negotiation? Social Theory \& Health, 5(4), 356-377. https://doi.org/10.1057/ palgrave.sth. 8700103
Smith-Carrier, T., \& Neysmith, S. (2014). Analyzing the interprofessional working of a home-based primary care team. Canadian Journal on Aging/La Revue Canadienne Du Vieillissement, 33(3), 271-284. https://doi.org/10.1017/ S071498081400021X

Sterie, A.-C., \& González-Martínez, E. (2017). Newcomer nurses' telephone calls to porters and doctors: Inquiring and reporting as vehicles for requests. In S. Pekarek Doehler, A. Bangerter, G. de Weck, L. Filliettaz, E. GonzálezMartínez, \& C. Petitjean (Eds.), Interactional competences in institutional settings. From school to the workplace (1st ed., pp. 143-168). Palgrave Macmillan.

Thomson, K., Outram, S., Gilligan, C., \& Levett-Jones, T. (2015). Interprofessional experiences of recent healthcare graduates: A social psychology perspective on the barriers to effective communication, teamwork, and patient-centred care. Journal of Interprofessional Care, 29(6), 634-640. https://doi.org/10.3109/13561820.2015.1040873

West, C. (1990). Not just “doctors' orders": Directive-response sequences in patients' visits to women and men physicians. Discourse \& Society, 1(1), 85-112. https://doi. org/10.1177/0957926590001001005

Zwarenstein, M., Rice, K., Gotlib-Conn, L., Kenaszchuk, C., \& Reeves, S. (2013). Disengaged: A qualitative study of communication and collaboration between physicians and other professions on general internal medicine wards. $B M C$ Health Services Research, 13(1), Article 494. https://doi. org/10.1186/1472-6963-13-494

\section{Author Biographies}

David Pichonnaz is a sociologist of work and professions, specialized in the study of public service relational work (police, healthcare, social work). His research focus on professional socialization, intraprofessional heterogeneity and interprofessional collaboration.

Liliane Staffoni's double degree in physiotherapy and psychology allows her to make the link between theoretical models and healthcare practice. Her research focuses on understanding the implementation of collaborative practices in different hospital settings.

Camille Greppin-Bécherraz is a sociologist specialised in health care and collaborative practice. She is involved in health promotion and education.

Isabelle Menia-Knutti works as an independent physiotherapist in her own private practice and collaborated in different research projetcs at the University of Applied Sciences and Arts (HESAV, HES-SO).

Veronika Schoeb's research interests lie in analysing communication interaction and interprofessional collaboration. As a physiotherapist and sociologist, she is able to bridge the gap between healthcare practice and social sciences. 